Tohoku J. Exper, Med., 1960, 72, 42-58

\title{
Histological and Histochemical Observations on the Developing Pancreas of Fetal Mouse
}

\author{
By \\ Tom Mori and Akinobu Haga \\ From the Department of Anatomy, Tohoku University \\ School of Medicine, Sendai
}

(Received for publication, December 2, 1959)

In most of the previous studies concerning the ontogenesis of the pancreas, the special attention of the investigators has been centered on the development of the islets of Langerhans, since in the pioneer works of Laguesse ${ }^{1 / 2}$ two successive stages in the development of the islets, îlots primaires and îlots secondaires, were described. According to Laguesse's opinion, the ilots primaires are derived from the primitive cell cord or the primitive tubules of the dorsal pancreatic anlage and form large masses of the islet cells, the îlots composées. Then, they undergo degeneration accompanying the formation of the excretory acini, from which the illots secondaires differentiate through the de-differentiation of the acinar cells. Furthermore, Laguesse stated that such an acino-insular transformation may even take place in an opposite direction (théorie de balancement).

These two steps in the development of panereatic islets were confirmed later by many researchers, some of them calling the primordia of the islets corresponding to the primary islets by special names such as "Inselanlagen" $\left(\right.$ Siwe $\left.{ }^{3 \prime}\right)$ or "primäre grosse Inseln" (Yasunaka"). But the "théorie de blancement" was challenged by most of the investigators though some confirmed the acinar origin of the secondary islets such as Neubert ${ }^{5}$, Freise $^{6}$, Ferner and Stoeckenius ${ }^{7}$. Recently, Bencosme ${ }^{87}$ also observed the formation of the islet from the undifferentiated primitive islet cells intercalated in the glandular epithelium of the excretory part, but he emphasized that there was no evidence of direct transformation of the fully developed acinar cells into the islet cells. This point of the problem under dispute dealing with the origin of the islet has been reviewed by Siwe ${ }^{3)}$ and Bargmann".

The primitive islet cells belonging to both the primary and the secondary islets were usually described by most of the authors as the cells stained deeply with eosin and containing pale stained vesicular nucleus. Some of them nominated these cells by such special names as "cellule trouble" (Laguesse), "trübe Zellen" (Neubert), or "muddy cells" (Warren and LeCompte ${ }^{10)}$ ), according to 箖䈏，芳贺昭揬 
their characteristic appearance in the sections.

Regarding the histochemical properties of these developing islet cells, McAlpine $^{11}$ pointed out an intense activity of alkaline phosphatase in fetal and neonatal rats, and Hultquist and Thorell ${ }^{12)}$ described a high content of ribonucleic acid (RNA) in the primitive islet cells arranged in the wall of the pancreatic duct of human fetal specimens.

In this work, chronological alterations during the differentiation in some histochemical properties of the exocrine and the endocrine cells of the mouse pancreas are observed. During the course of the study, although the histochemical characteristics were mainly treated, a general observation of the histogenetical process of the pancreas was also made under an attempt to give some contribution to the problem dealing with the origin of the pancreatic islets.

\section{MATERIAL AND METHODS}

Fetus of dd-strain mouse sampled at the half day-intervals from $9 \frac{1}{2}$ to $19 \frac{1}{2}$ days of pregnancy were used. The latter time period is just before the birth in this strain of mouse. The ages of the fetus were computed from the observed time of successful copulation, the same hour in the next day being dated as the end of the first day of pregnancy.

The specimens for the detection of alkaline and acid phosphatases and lipase were fixed and dehydrated in chilled acetone, while those for determining the ribonucleic acid (RNA) were fixed in Carnoy's fluid. A part of the specimens was also fixed in Zenker-formol or in $10 \%$ formalin. All the specimens were imbedded in paraffin, and cut serially in transverse plane at $5-8 \mu$.

The detection of the enzyme activities was carried out according to the method of Gomori ${ }^{13)}$, using sodium beta-glycerophosphate, a mixed preparation of alpha- and betaglycerophosphate and "Tween 60 " as the substrates for alkaline phosphatase, acid phosphatase and lipase, respectively. The incubation was done without previous deparaffnization of the sections. The distribution of RNA was tested by staining the Carnoy-fixed sections with methyl green and pyronin, and partially with chrome alum gallocyanin of Einarson ${ }^{14)}$. Specimens fixed in Zenker-formol were used for the general observations on the histogenesis after the staining with hematoxylin and eosin (H-E), except some sections stained with Altmann's anilline water-acid fuchsin and picric acid which yields a brilliantly red tint of the zymogen granules. Those fixed in formalin were stained with Gomori's ${ }^{15)}$ aldehydefuchsin (A-F) according to the slight modification of Mori, Fujimori and Kato ${ }^{16}$ ) in order to detect the beta-cell-granules.

\section{OBSERVATIONS}

General description of the histogenesis and the distribution of RNA.

91 to $10 \frac{1}{2}$ days: The dorsal anlage of the pancreas was initially found in the fetus of 91 days of gestation as an epithelial cell cord containing a considerably wide evagination from the intestinal cavity in its proximal part. The ventral pancreatic anlage appeared on the 10th day as a well-defined evagination taking its origin from the proximal part of the hepatic diverticulum adjacent to the primitive duodenum. The cytoplasm of the cells of both the dorsal and the ventral anlagen was stained intensely with pyronin, especially in the cells situated in the peripheral and distal parts of the anlagen. In the dorsal pancreas 
of 10 days, a small number of cells were stained with pyronin more intensely than the remaining cells of the anlage. These intensely basophilic cells were found intermingled with the epithelial cells, or in the small groups at the distal end of the anlage, suggesting the emigration and protrusion of these cells out from the deep part of the dorsal anlage (Fig. 1).

In the slightly advanced embryos dated $10 \frac{1}{2}$ days, the specific cells noticed in the 10-day-specimens with dominant cytoplasmic basophilia were found in larger groups attached at the posterior end of the dorsal anlage (Fig. 2). The basophilia was however markedly reduced in this stage, the majority of these cells revealing less affnity to pyronin than the cells in the main part of the dorsal pancreas. They were considerably large, and showed indistinct outline of the cell body. The nuclei were also large and palely stained with methyl green, since the chromatin particles contained were rather fine. In the sections stained with H-E., these specific cells were well defined by the eosinophilic cell body surrounding a vesicular nucleus from the darkly stained main cells of the anlage. The mass of these eosinophilic cells is undoubtedly just the primary islet described by many authors in man and in various animals, and the "primäre grosse Insel" described by Yasunaka" in fetal mouse.

11 to $11 \frac{1}{2}$ days: The diverticulum in the dorsal pancreatic anlage almost disappeared leaving a soild cell cord, the primitive dorsal pancreatic duct, connecting the distal part of the anlage and the duodenum. The outline of the dorsal pancreas became uneven by slight bulging out of the cells in many parts of the anlage. The most superficial cells of the anlage took an appearance of simple columnar epithelium, the cytoplasm of which showed an intense affinity to pryonin. The masses of the primary islets, which stood out by diffuse and pale tint of the cytoplasm, were found in a local fusion with each other.

12 to $12 \frac{1}{2}$ days: The outline of the dorsal anlage became very irregular by prominent bulgings in many parts of the anlage. These bulges were separated from each other by deep indentations containing mesenchyme tissue and blood capillaries. This change sets to the ramification of the primary pancreatic tubules and the adenomere formation (Fig, 3). Corresponding to these ramifications and the formation of the primitive acini, the epithelial cells forming the surface of these bulges were stained intensely with pyronin, while the cells in the internal part of the dorsal pancreas were arranged less dense and showed rather limited cytoplasmic basophilia. The mass of the primary islets was stained diffusely and faintly with pyronin, and the various parts of the islets were found scattered between the bulgings of the anlage, sometimes being in touch with them. In the dorsal pancreas of this stage, especially after $12 \frac{1}{2}$ days, a new formation of the islets took place from the walls of the tubules which now had minute tubular cavities. In the H-E-stained sections, these new islets were observed as small groups of cells stained diffusely and remarkably with easin and were protruding 
perpendicularly from the walls of the tubules (Fig. 3). The similar cells in other specimens showed only a limited affinity to pyronin, and to chrome alum gallocyanin, either. These new islets deriving from the duct system are just what were nominated as "primäre kleine Inseln" by Yasunaka", and we think that they are the seconary islets in the earliest stage.

13 to $13 \frac{1}{2}$ days: The formation of the excretory units became very distinct in the major parts of the dorsal pancreatic anlage. Some terminal buds of the acinus took a spherical form having a wide acinar cavity which was in communication with the tubular cavity. From the side wall of the duct, too, many primitive acini were projecting in spherical or semi-spherical bulges. The cells of these terminal and side buds stained very strongly with pyronin, especially the juxtanuclear area of their cytoplasm was loaded with a coarse basophilic substance. The nucleus usually contained two or three or more large and angular nucleoli which were also colored brilliantly red with pyronine. The cells of the duct system were less basophilic and their nucleoli were also smaller than those of the acinar cells in number and size. So, the boundaries of most acini to the adjacent duct cells were always clearly distinguished by an abrupt change in morphology of these two kinds of cells, especially by the marked difference in the intensity of cytoplasmic basophilia. The cells of the islets, including those of both the primary and the secondary ones, showed only a faint and diffuse tint after the staining with pyronin or gallocyanin.

From the walls of the fine primitive tubules of the ventral anlage of this stage, too, small groups of rather faintly stained cells were projecting. This was regarded as the first appearance of the secondary islets in the ventral pancreas, where, unlike in the dorsal one, no primary islet preceded the development of the secondary islet.

14 to $14 \frac{1}{2}$ days: The development of both the exocrine and the endocrine parts was greatly advanced. The cytoplasmic basophilia of the acinar cells became very conspicuous, and the perinuclear and the basal parts of most of the acinar cells were filled with numbers of coarse granules or thread-like substance which exhibited an intense affinity to pyronin.

The islets tended to unite with each other to form large band-like masses extending along, and partially connecting with, the duct. Yasunaka" discriminated this band-like formation of the islets from the preceding perpendicular projecting, and used the appelation of "sekundäre kleine Inseln" for these islets. The cells of these islets were also faintly stained with pyronin and gallocyanin (Fig. 4). As will be described below in the description concerning the phosphatase activity, the differentiation of the new islet cells from the duct wall is in progress throughout various parts of the pancreatic anlage, especially after 13 days and 6 hours. However, it was very difficult to point out each primitive islet cells arranged in the duct epithelia in the sections stained with methyl green and pyronin, or with 
chrome alum gallocyanin, either in this or in the preceding stage. Only occasionally, single cells with intensely but diffusely basophilic cytoplasm were found intermingled among the cells of the duct epithelium, but we could not identify them with the primitive islet cells, since the number of these basophilic cells was far below that of the primitive islet cells standing out by their high phosphatase activity in the specimens of the same developmental stage.

15 to $15 \frac{1}{2}$ days: In the specimens of 15 days stained by Altmann's method, a few acinar cells were found containing minute granules stained with acid fuchsin, although the fuchsinophilia was yet indistinct and the number of the granules was very small. A half day later, this granules became larger in number and size, and the affinity to acid fuchsin was also highly enhanced. This may be identified as the zymogen granules.

In the dorsal pancreas, the composed mass of the islet was in a form of thick band extending along the duct or in a bridge-like cord of cells connecting the branches of the duct and occasionally acini. In a very limited number of these islet cells, fine beta-granules were stained faintly but distinctly with A-F.

16 to $19 \frac{1}{2}$ days: The dorsal and the ventral anlagen of the pancreas tended to join each other on the 16th day. After that, according to the rapid proliferation and enlargement of the excretory acini, the proportion of the interstitial connective tissue decreased. Most of the acinar cells came to contain many zymogen granules in the apical portion of their cell bodies before $17 \frac{1}{2}$ days, and the intensity of the cytoplasmic basophilia looked considerably reduced with the rapid appearance of the granules. The cavity of the proximal part of the dorsal pancreatic duct tended to disappear, and the basophilia of the epithelial cells in this portion of the duct was apparently less intense than in the other part of the duct. The beta granules showed a steady increase until they became apparent in a greater number of the islet cells in both the dorsal and the ventral parts of the pancreas on the 18th day. After the 18th day, the large masses of the islets underwent a separation into elliptic or spherical groups of cells, suggesting the formation of the definite Langerhans' islets.

Activities of alkaline and acid phosphatases and lipase.

In the following, the description is mainly centered on the distribution of alkaline phosphatase, since the activity of this enzyme is looked upon as to be more closely related to the differentiation of the islets than the other enzymes. As for acid phosphatase, only cursory accounts are presented because our results on the distribution of this enzyme often contained some irregularities.

$9 \frac{1}{2}$ to $10 \frac{1}{2}$ days: At the initial stage of the formation, both the dorsal and the ventral anlagen of the pancreas revealed an intense activity of alkaline phosphatase, especially in the solid distal parts. This enzymic activity began to decrease in the subsequent stages, especially rapidly in the dorsal anlage, while 
in the ventral one such a decline in the enzymic activity progressed more slowly leaving a perceptible black tint until the 12th day. In the dorsal anlage of 10 days, a small number of cells showing a high activity of alkaline phosphatase were found intermingled with the faintly stained cells, and some of these strongly reactive cells were in small groups attached to the distal end of the anlage (Fig. 5). A half day later, these cells of high phosphatase activity constituted a few large masses protruding from the distal part of the dorsal pancreas. This mass is undoubtedly the primary islet described above. A distinct activity of the enzyme was also observed in the proximal opening of the ventral pancreatic duct to the choledochus of $10 \frac{1}{2}$ days but this reaction disappeared in the succeeding stage.

The activity of acid phosphatase also looked slightly higher in the primary islets than in the main part of the dorsal pancreas of $10 \frac{1}{2}$ days.

11 to $11_{2}$ days: Along with the adenomere formation and the ramification of the tubules, the superficial cells of the dorsal pancreas showed a slight alkaline phosphatase activity corresponding to the bulging. As for the acid phosphatase, only moderate and diffuse reaction was observed throughout the anlagen, no noticeable difference being perceived between the cells of the primary islets and those of the main part of the anlage.

12 to $12 \frac{1}{2}$ days: As illustrated in Fig. 6, the outline of the dorsal anlage to the surrounding mesenchyme was not clearly defined, since the enzymic activities shown in both the tissues were almot on the same level of intensity. But the distal part of the dorsal anlage showed a distinct reactivity, especially in the primary islet and the epithelial bulges. A small number of highly stained cells were also observed inside the dorsal pancreas but these cells were not yet identified with the primitive cells of the secondary islet with certainty.

13 to $13 \frac{1}{2}$ days: With the rapid progress of the formation of the excretory acini and the general expansion of the anlage, the activity of alkaline phsophatase in the primitive acinar cells was considerably ehnanced (Fig. 7), but this reactivity diminished in the subsequent stage. In a specimen of 13 days and 6 hours, as shown in Fig. 7, we could point out intensely and definitly reactive cells intercalated in the barely stained duct epithelium, while in the 13-day-fetus, only a faint and doubtful reaction was found in a very limited number of cells arranged in the walls of the tubules. Later on, these highly stainable primitive cells of the secondary islet increased in number, and were most frequently found in the small branches of the duct including the terminal portion of the tubules adjacent to the acini. The primary islet still retained a slight activity of alkaline phosphatase.

The activity of acid phsophatase was moderate and rather diffuse, but in some specimens of $13 \frac{1}{2}$ days, a distinct reaction was found fairly restricted to the duct and the developing islets. 
14 to 15 days: The primitive cells of the secondary islets showing a high activity of alkaline phosphatase were found most frequently in this stage. They were observed either as single cells arranged in the tubular epithelia or as small groups protruding laterally from the tubules (Figs. 8 and 9). Some of the centro-acinar cells also revealed an intense activity of this enzyme, though only on very rare occasions (Fig. 10). In this stage, such an intense enzymic activity was fairly restricted to the primitive islet cells, while the band-like mass of the islets showed only a faint or almost imperceptible tint.

The acid phosphatase reaction was observed mainly in the duct system and the islets, but it was not so clearly restricted to the latter as in the case of the alkaline phosphatase.

After 15 days, a minute amount of granular precipitates of pale-brown color could be observed in some of the acinar cells after the treatment for detecting the lipase activity.

$15_{\frac{1}{2}}$ to 17 days: The intra-tubular primitive islet cells rapidly decreased in number unitl they had entirely disappeared by the 16th day. The islets went on growing and uniting with each other to form the larger complex masses, and the cells of these masses of the islets tended to resume a slight activity of alkaline phosphatase. In the specimens ranging from $15 \frac{1}{2}$ days to $16 \frac{1}{2}$ days, many cut surfaces of the islets were often standing out by their faint but distinct black tint against the other constitutents of the pancreas. The walls of the duct remained almost colorless, and some of the acinar cells showed very slight and granular reaction in the apical portion of the cell body.

After the treatment for detecting the acid phosphatase activity, very intense reaction of the duct and the islest was obtained, and the most of the acinar cells showed also a moderate reaction, especially in the nucleus (Fig. 12).

In the specimens of $16 \frac{1}{2}$ days, the precipitates representing the activity of lipase became rather coarse and their brown tint looked deeper than in the foregoing stage, but the amount was still small.

$17 \frac{1}{2}$ to 191 days: In this stage, the activity of alkaline phsophatase in the islets gradually diminished until a faint activity was left in the nuclei. But in the specimens of 19 days and $19 \frac{1}{2}$ days, a small number of cells located in the peripheral area of each definite islet often showed a moderate reaction in their cytoplasm and nucleus, this finding being in good agreement with that of McAlpine ${ }^{11}$.

The activity of acid phosphatase suffered little reduction in the islets while that in the acinar cells almost diminished away after the 18th day (Fig. 13).

The activity of lipase was gradually intensified in this stage and most of the acinar cells came to contain coarse granular precipitates after $17 \frac{1}{2}$ days. The color of the precipitate also became deeper and deeper. The cells of the duct wall and the islets remained entirely negative to the lipase reaction. 


\section{DISCUSSION}

Brachet ${ }^{17) 18 / 19 / 20)}$ and Caspersson ${ }^{2122)}$ greatly advanced our knowledge on the localization and the function of nucleic acids inside the cell using excellent technics which they devised, and the pancreas was one of the organs used in their early works on this subject (Brachet ${ }^{17) 18}$ ) and Caspersson, Landström-Hydén and Aquilonius ${ }^{23)}$ ). Since then, thanks also to repeated examinations by numbers of researchers, it is nowadays widely known that the so-called ergastoplasm of the pancreatic acinar cells contain a large amount of RNA, while the islet cells almost lack in RNA (Vendrely and Vendrely ${ }^{24)}$ ).

As for the other histochemical characteristics of the pancreas, Gomori ${ }^{25}$ pointed out that the pancreas of mouse entirely lacked in the activity of alkaline phosphatase except in the capillary walls and in some parts of the duct system, and a selective localization of acid phosphatase in the islets was described by Noback and Montagna ${ }^{26}$. Our findings in the older fetus agree with those wellknown histochemical properties of the adult pancreas.

Except McAlpine ${ }^{11}$ and Hultquist and Thorell ${ }^{12)}$, the fetal pancreas was not so often treated as the subject of histochemical studies in the past, and rather cursory accounts were made in the general observations on the distribution of phosphatases in the fetal organs by Moog'29), Rossi et al. ${ }^{27 / 28)}$ and others. Our study presented more details in the chronological alterations in some histochemical reactions of the developing pancreas, and the distribution of alkaline phosphatase observed was in an excellent agreement with McAlpine's findings in fetal and neonatal rats.

The most important finding in our study was the markedly enhanced activity of alkaline phosphatase in the primitive cells of both the primary and the secondary islets, and by this characteristic localization of the enzyme, as in the case of rat described by McAlpine, we could detect an initial appearance of the primitive islet cells about half a day before they became apparent in the sections treated with routine histological staining. In our preparations, however, such an intense activity of the enzyme is fairly restricted to the primitive cells which are just in the way of initial differentiation, and after that, they usually tend to lose their specific enzymic activity. Only the primary islets retain their slight reactivity until $131_{2}$ days, but with the formation of the band-like large mass of the islet, most of the islet cells lose their selective stainability. In the specimens ranging from the 15 th to 16 th day, the islet cells resumed temporarily a faint activity of alkaline phosphatase coinciding with the appearance of the beta granules in the greater number of the cells.

The slightly phosphatase-positive cells in the peripheral area of the fully developed islet may be the primitive alpha cells as considered so by McAlpine. It is very possible to think that the beta cells precerle the alpha cells in the 
development, since the most of the islet cells have been found containing beta granules on the 18th day, while the phosphatase-active peripheral cells have been observed in the specimens of later stage. Such a preceding formation of the beta cell also coincides with the findings of McAlpine, Hard ${ }^{30)}$, Bencosme ${ }^{8}$, Munger ${ }^{31}$ and others. So, as has been described by Bencosme, the primitive cells of the secondary islet found arranged in the walls of ducts in our preparations may therefore most likely correspond to the primitive beta cells.

The acinar cells also revealed distinct activity of alkaline phosphatase at the initial stage of the development showing an epithelial alignment and a convex bulging. It may be postulated, therefore, that the activity of this enzyme participates to some extent in the metabolism of cells underlying the morphological specialization during the differentation and maturation. Such a probable relationship between morpho- and histogenetic process and the activity of the enzyme was first described by Moog 27) in ehick embryos, and later, extensively discussed by Rossi et al. ${ }^{32)}$, Mulnard ${ }^{33)}$ and Borghese ${ }^{34)}$. McAlpine also suggested that this enzyme is more closely linked to the differentation of the islet cell than to the proliferation of the cell.

The most initial stage of the differentiation of the primary islet cells from the primitive cell cord of the pancreatic anlage was also characterized by an intense cytoplasmic basophilia besides the distinct positiveness of alkaline phosphatase described above. A half day later, however, this basophilia rapidly diminished and its intensity became feebler than that of the other cells of the pancreatic anlage. After that, all the cells of the primary and secondary islets retained a low content of RNA throughout the whole stage of their pre-natal development, as has been already described by Hultquist and Thorell ${ }^{12)}$, and by Hinrichsen (unpublished data cited in Vendrely's review $\left.{ }^{24}\right)$ ). But, unlike the findings of Hultquist and Thorell, there was little evidence that the primitive islet cells found arranged in tubular epithelium carried a high content of RNA, and our results rather suggested that these primitive islet cells in later stage were less basophilic than the proper duct cells. Recently, Munger ${ }^{31)}$ described in his electronmicroscopical study on the developing pancreas of mouse that the primitive islet cells of 13-day-embryos appeared "comparatively dense due to numerous ergastoplasmic granules filling the cytoplasm", while in those from. 15-day-specimens the ergastoplasmic granules decreased in amount. Then, it may be deemed that the staining technic for the cytoplasmic RNA with pyronin and gallocyanin used in this study failed to demonstrate such a slight accumulation of RNA in the primitive cells of the secondary islets.

The acinar cells on the other hand revealed a large content of RNA from the first stage of their development. It was noticed that every small acinus in the very early stage of development, even those consisting of a small number of cells and just protruding out from the duct, showed a high content of RNA in their 
cytoplasm and nucleoli. But an intense basophilia which lasts into the later stage of development is not merely related to the growth and differentiation but also to the formation of the zymogen granules. This assumption may also be supported by an apparent reduction of the cytoplasmic basophilia accompanying the rapid appearance of the zymogen granules during 16 to $17 \frac{1}{2}$ days, such an inverse trend in the amount of cytoplasnic RNA and the zymogen granules being in fairly good agreement with the densitometric observations of Oram ${ }^{35}$ ) on the secretory cycle of the pancreatic acinar cells.

From these findings, it may be concluded that RNA also participates in the cellular differentiation during the ontogenesis, as has been pointed out by Caspersson and Thorell ${ }^{36)}$. On this problem, basing mainly on the histo- and cytochemical data, Brachet (9/20/37/38/39) and Caspersson ${ }^{21 / 22 /}$ discussed repeatedly, and they mostly emphasized a possible participation of RNA in the intracellular synthesis of protein. Recent progress in the bicohemical researches on the biological role of nucleic acids also tends to substantiate this hypothesis, and

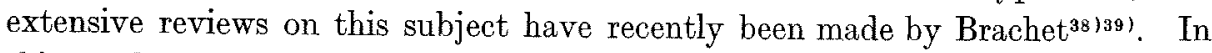
this study, however, the activity of alkaline phosphatase is apparently more closely linked to the differentiation, especially in the endocrine cells of the pancreas. In spite of occasional irregular results, the activity of acid phosphatase also seemed to be related to some extent to the initial differentiation and further maturation of the islet cells. Since the iselts of adult animal also show an evident activity of this enzyme (Noback and Montagna ${ }^{26}$ ), it may take part in the specific function of the islet cell, too. The activity of lipase is unquestionably related to the zymogen granules. It has been demonstrated only in the excretory cells of the older specimens having the granules.

Although the chronological alterations in histochemical properties during the development of the endocrine and the exocrine cells of the pancreas was the primary concern in this report, other problem dealing with the histogenesis, especially that of the islets of Langerhans was also studied. In general, the histogenetical process observed in this study was very similar to the description of Yasunaka" on mouse, and the two stages of the islet formation were confirmed. In this study, the characteristic localization of alkaline phosphatase made it very obvious that the cells of the primary islets were derived from the primitive cord of the dorsal pancreas while those of the secondary islets principally originated from the walls of the pancreatic tubules. Any intimate relation between the developing primary islets and the sympatheitc ganglia described by Van Campenhout ${ }^{40}$ ) has not been confirmed. There was little evidence about the acinar origin of the islet cells except only the occasional and questionable existence of phosphatase-positive cells in the primitive acini. As has been mentioned above, the primitive islet cells found arranged in the duct epithelia have been regarded as the primitive beta cells for the time being, but further studies should be done 
on this problem, since some of these cells have been looked upon as the primitive alpha cells by some anthors such as Ferner and Stoeckenius?', and Hultquist and Thorel1'12).

\section{SUMMARY}

The intracellular distribution of alkaline and acid phosphatases, lipase and RNA in the developing pancreas of fetal mouse was observed histochemically. During the course of this study, general observations on the histogenesis of the pancreas, especially that of the islets of Langerhans, were also carried out. The findings may be summarized as follows:

1. Two successive developmental stages of the islets, the primary and the secondary, were confirmed. No degeneration of the primary islets was however established.

2. The primary islets initially appeared in the dorsal anlage of the pancreas of 10 days as the masses of cells showing an intense basophilia and a high phosphatase activity. The amount of cytoplasmic RNA was rapidly decreased thereafter.

3. The secondary islets appeared in the dorsal anlage of $12 \frac{1}{2}$ days, while those in the ventral anlage was first observed one or half a day later. The tubular origin of the secondary islets was confirmed, and the primitive cells of this generation of the islets were characterized by an intense activity of alkaline phosphatase. No specific accumulation of RNA in these cells was detected by the staining with pyronin and chrome alum gallocyanin.

4. The activity of acid phosphatase was also fairly restricted to the islets and the duct from the early stage of development, and the activity lasted until the latest date of the intra-nterine life.

5. The activity of lipase was observed only in the fully developed excretory cells having the zymogen granules.

\section{References}

1) Laguesse, M.E., Compt. rend. Soc. biol., 1893, 45, 819.

2) Laguesse, M. E., Compt. rend. Soc. biol., 1895, 47, 699.

3) Siwe, S.A., Gegenbaurs Morph. Jb. 1926, 57, 84.

4) Yasunaka, M., Kaibogaku Zassi (Jap. with Germ. abstr.), 1937, 10, 63.

5) Neubert, K., Roux's Arch. Entw.Mech. 1927, 111, 29.

6) Freise, G., Z. mikr.-anat. Forsch., 1929, 17, 185.

7) Ferner, H. \& Stoeckenius, W.Jr., Zschr. Zellforsch., 1949, 35, 147.

8) Bencosme, S.A., Am. J. Anat., 1955, 96, 103.

9) Bargmann, W., Möllendorffs Handbuch mikr. Anat. Mensch., Julius Springer, Berlin, 1939, VI/2, 197.

10) Warren, S. \& LeCompte, P.M., The pathology of diabetes mellitus, 3rd Ed., Lea and Febiger, Philadelphia, 1952, Chapt. II, 15. (Cited by Bencosme ${ }^{8)}$ ).

11) McAlpine, R.J., Anat. Rec., 1951, 109. 189.

12) Hultquist, G.T., \& Thorell, B., Acta path. microbiol. Scand., 1953, 32, 245. 
13) Gomori, G., Microscopic histochemistry, University of Chicago Press, 1952.

14) Einarson, L., Am. J. Path., 1932, 8, 295.

15) Gomori, G., Am. J. Clin. Path., 1950, 20, 665.

16) Mori, T., Kato, S. \& Fujimori, N., Tohoku J. Exper. Med., 1958, 68, 1.

17) Brachet, J., Compt. rend. Soc. biol., 1940, 133, 88.

18) Brachet, J., Arch. de Biol., 1942, 53, 207 (Cited by Brachet ${ }^{38)}$ and Vendrely24).

19) Brachet, J., Symp. Soc. Exper. Biol., 1947, 1, 207.

20) Brachet, J., Ann. New York Acad. Sci., 1950, 50, 815.

21) Caspersson, T., Naturwiss,., 1941, 17, 33.

22) Caspersson, T., Cell growth and cell function, Norton \& Co. Inc., New York, 1950.

23) Caspersson, T., Landström-Hydén, H. \& Aquilonius, L. Chromosoma, 1941, 2, 111.

24) Vendrely, C. \& Vendrely, R., Handbuch der Histochemie (Ed. by Graumann, W. \& Neumann, K.), Gustav Fischer, Stuttgart, 1959, 111/2, 84.

25) Gomori, G., J. Cell. Comp. Physiol., 1941, 17, 71.

26) Noback, C.R. \& Montagna, W., Am. J. Anat., 1947, 81, 343.

27) Moog, F., Biol. Bull., 1944, 86, 51.

28) Rossi, F., Pescetto, G.\& Reale, E., Zschr. Anat. Entw-Gesch., 1950, 115, 500.

29) Rossi, F., Pescetto, G.\&. Reale, E., Zschr. Anat. Entw.-Gesch., 1953, 117, 36.

30) Hard, W.L., Am. J. Anat., 1944, 75, 369.

31) Munger, B.L., Am. J. Anat., 1958, 103, 275.

32) Rossi, F., Pescetto, G. \& Reale, E., Compt. rend. Ass. anat., 1954. 41, 1.

33) Mulnard, J., Arch. Biol., 1955, 66, 525.

34) Borhgese, E., Internat. Rev. Cytol., 1957, 6, 289.

35) Oram., V., Acta ant., Suppl. 23, 1955.

36) Caspersson, T. \& Thorell, B., Chromosoma, 1941, 2, 132.

37) Brachet, J., The nucleic acids (Ed. by Chargaff, E. \& Davidson, J.N.), Academie Press, New York, 1955, Vol. II, Chapt, 28, 475.

38) Brachet, J., Biochemical cytology, Academic Press, New York, 1957.

39) Brachet, J., Handbuch der Histochemie (Ed. by Graumann, W.\& Neumann, K.), Gustar Fischer, Stuttgart, 1959, III/2, 1.

40) Van Campenhout, E,. Arch. de Biol., 1925, 35, 45 (Cited by Bargman" and Bencosme $^{8)}$ ).

\section{Explanation of Figures}

\section{Plate I}

Fig. 1. The dorsal pancreatic anlage of a 10-day-embryo. The anlage mainly consisted of a thick epithelium forming an evagination of the mid-gut. From the distal part (upper in the figure) of the anlage lumps of intensely basophilic cells are migrating out. Stained with methyl green and pyronin.

Fig. 2. Low-power view of the dorsal anlage of $10 \frac{1}{2}$ days. The anlage still retains a small cavity. At the distal end of it, small primary islets are attached, of which cells are characterized by a diffuse and faint cytoplasmic basophilia, palely stained vesicular nucleus, and indistinct boundary of the cell body. Methyl green and pyronin. 
Fig. 3. The dorsal anlage of 12 days, showing an extensive progress of ramification of the tubules and formation of the primitive acini. From the walls of the tubules faintly basophilio cells of the secondary islets are being formed (SI). Some cut surfaces of the primary islet (PI) are also seen between, and partially connecting with, the tubules and acini. Hematoxylin and eosin.

Fig. 4. A low-power view of the dorsal pancreas of $14 \frac{1}{2}$ days stained with methyl green and pyronin. All the acini including those consisting of a few primitive acinar cells reveal a very intense affinity to pyronin. The epithelial cells of the duct rank the next in the cytoplasmic basophilia, while the islet shows generally only a limited affnity to pyronin except more perceptible staining in some of the small secondary islets attached to the duct.

\section{Plate II}

Fig. 5. Distribution of alkaline phosphatase in the distal part of the dorsal pancreatic anlage of 10 days. Most of the parenchymal cells are stained only faintly, among which intensely stained primitive cells of the primary islet are found intermingled. The mesenchymal tissue surrounding the pancreatic anlage exhibits a moderate activity of the enzyme.

Fig. 6. The dorsal pancreas of the 12-day-specimen stained for alkaline phosphatase. The superfical cells in the form of a convex columnar epithelium show an enhanced activity of the enzyme. The cell groups appointed by arrows form a primary islet, which is a large mass of the cells communicating with each other in the other sections. The more proximal part of the anlage surrounding a diverticle reveals weaker reaction, in which small number of highly stained cells are found scattered.

Fig. 7. The dorsal pancreas of 13 days and 6 hours. The primitive islet cells scattering in the walls of the tubules and some of the developing acini show a distinct activity of alkaline phsophatase.

\section{Plate III}

Fig. 8. Low-power view of the dorsal pancreas of 14 days stained for alkaline phosphatase. Many primitive islet cells arranged in the duot walls are standing out by their distinct activity of the enzyme against the feebly stained ducts and acini.

Fig. 9. Higher magnification of the pancreatic duct of 15 days stained for the same enzyme. The intensely reactive primitive islet cells are found sigularly intercalated in the duct wall or projecting out from the duct forming small masses.

Fig. 10. Shows highly reactive centro-acinar cells found in the same specimen illustrated in the preceding figure.

\section{Plate IV}

Fig. 11. Acid phosphatase reaction in the dorsal pancreas of $\mathbf{1 2}$ days. The central part of the anlage including the duct and the developing islets is stained most intensely.

Fig. 12. The same enzyme in the pancreas of 16 days. The walls of the duct and the islets are most reactive, and the acini show a moderately intense reaction, too.

Fig. 13. The distribution of the same enzyme in the pancreas of $18 \frac{1}{2}$ days. The definite islet in the center of the figure and the ducts exhibit very strong enzymic activity, while the reaction of the excretory cells is conspicuously reduced. 
Plate I

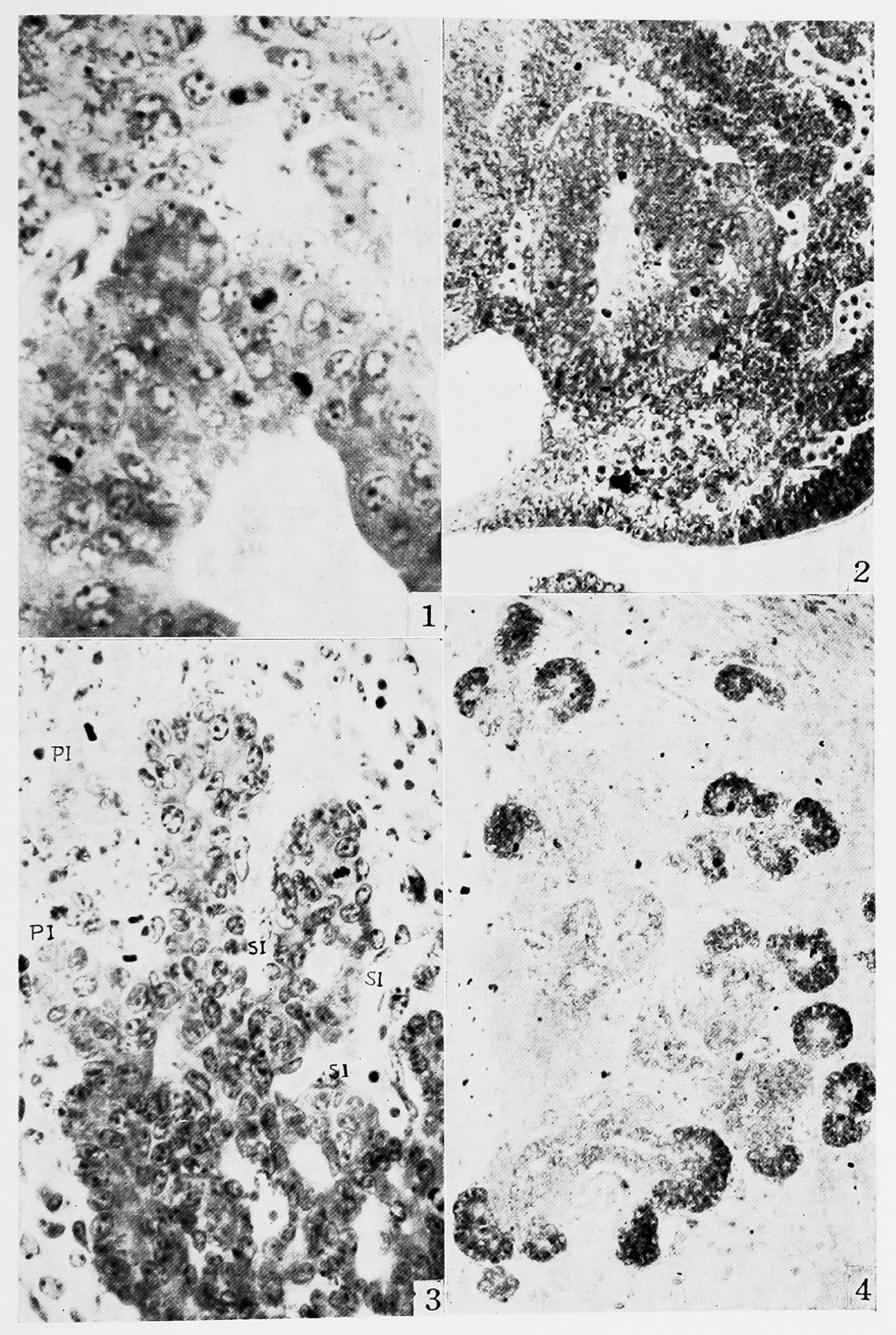


Plate II

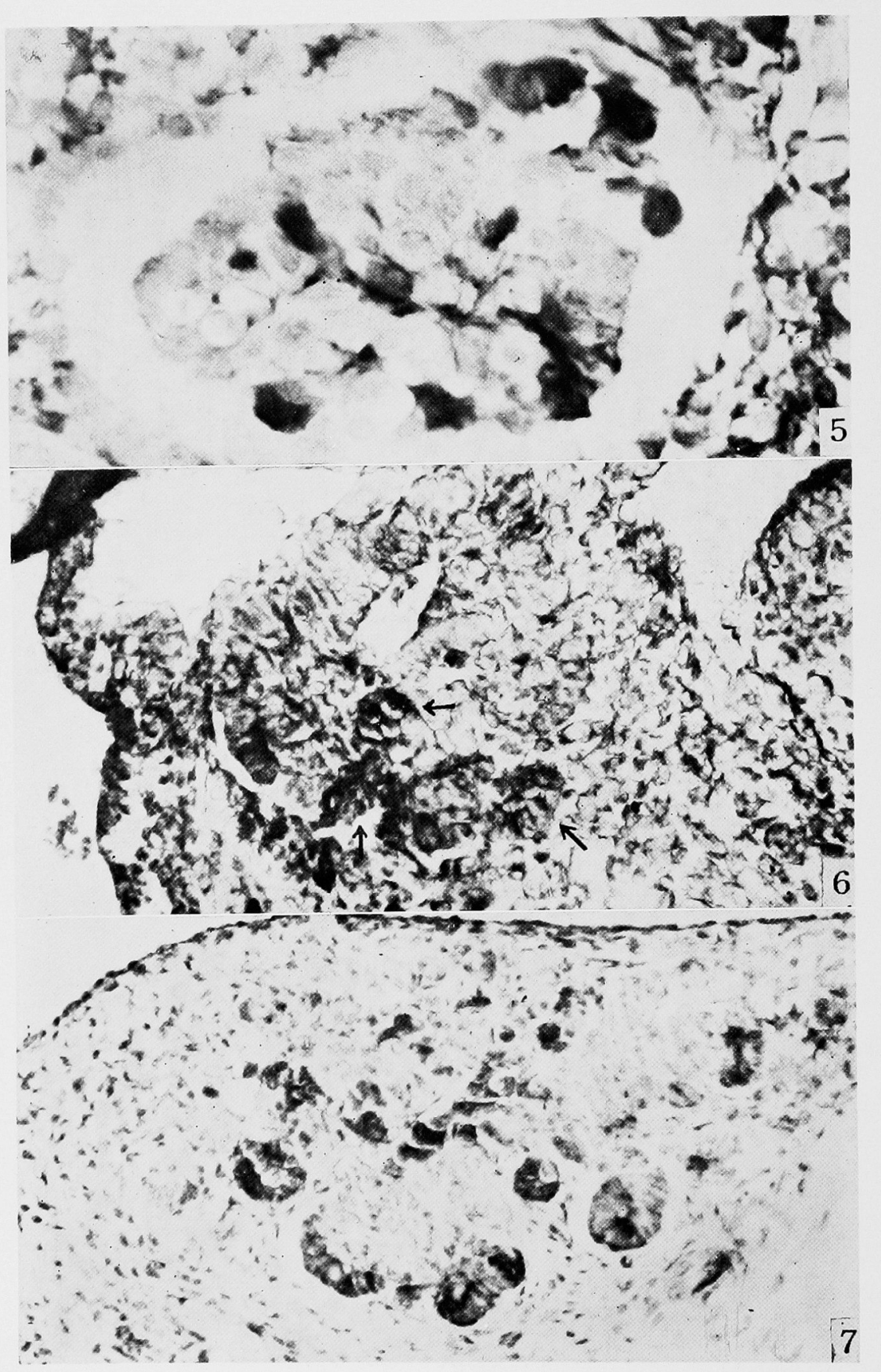


Plate III

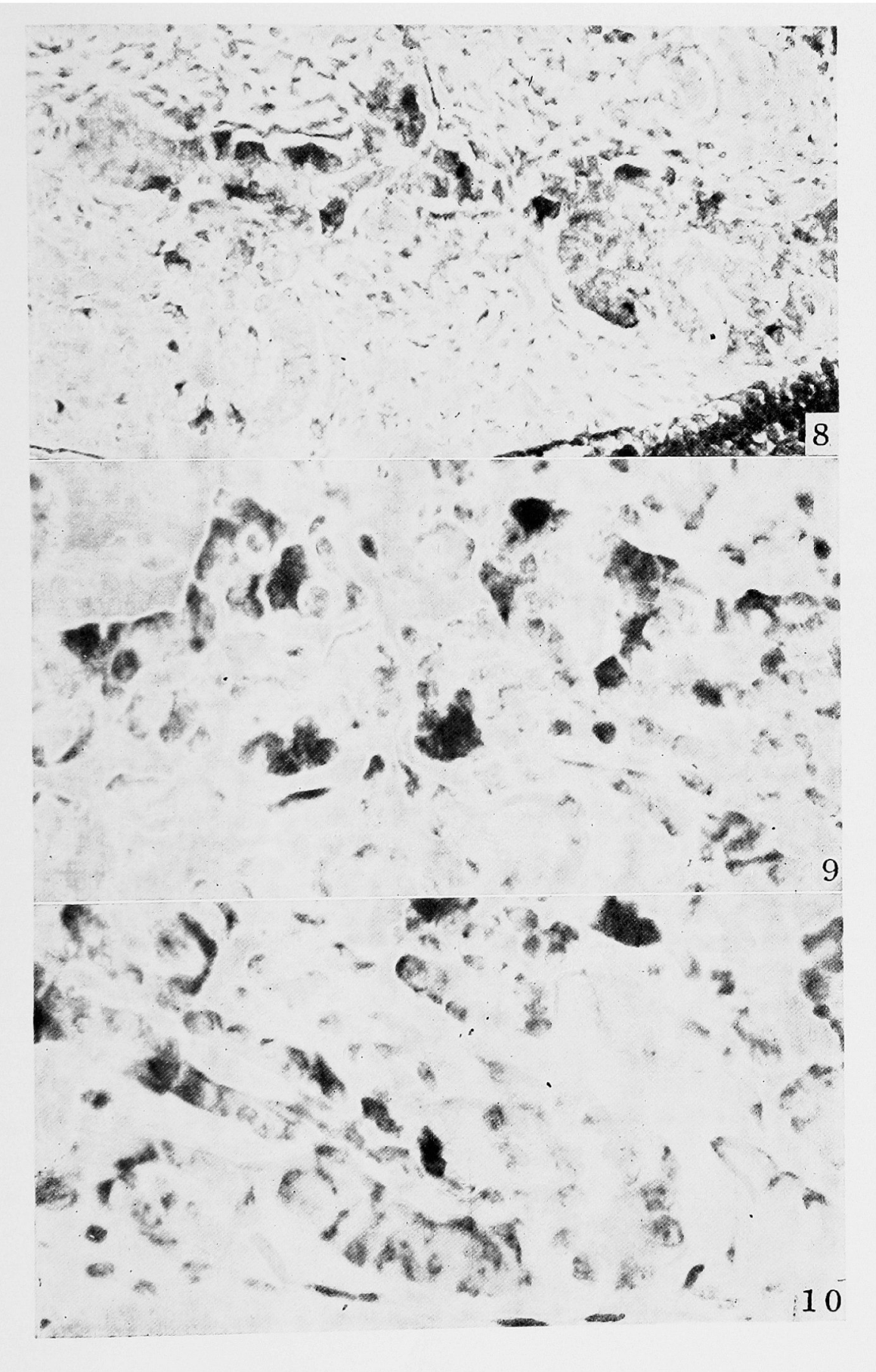


Plate IV

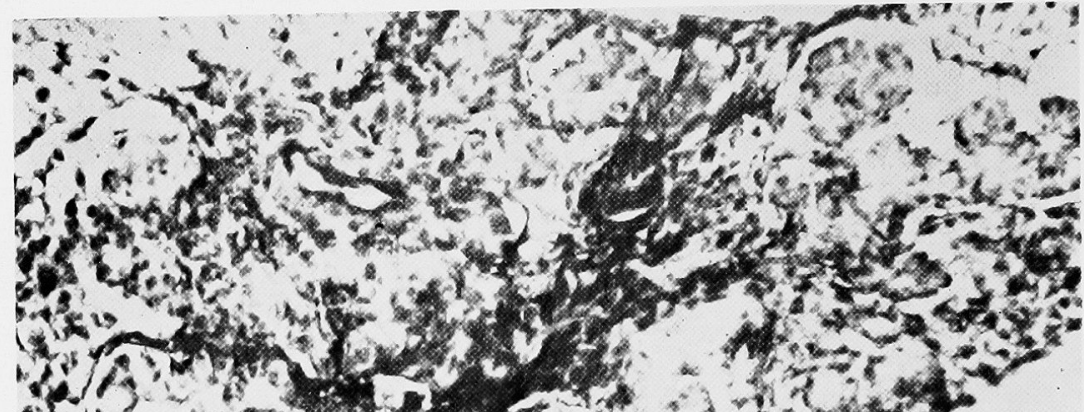

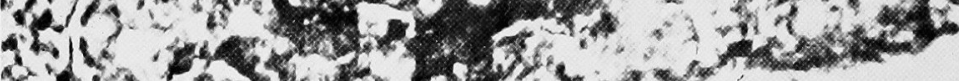

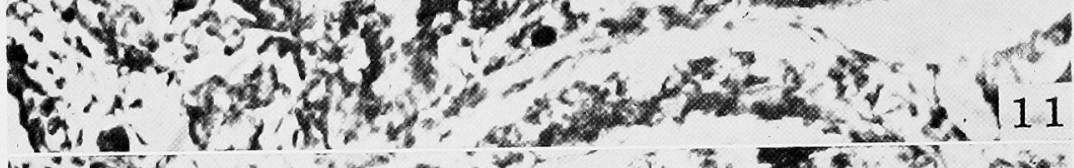
1.9.2.

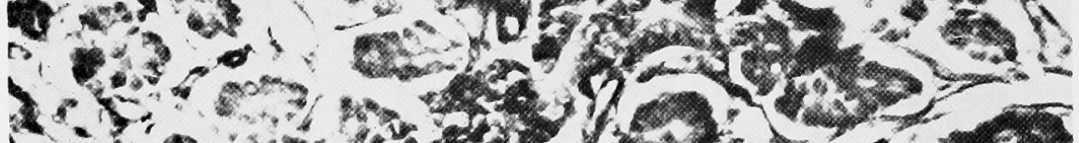
1.2.

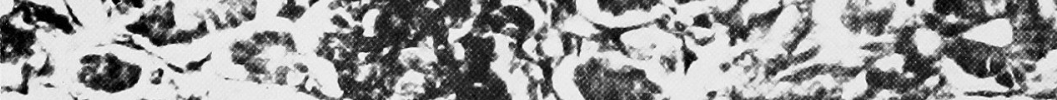

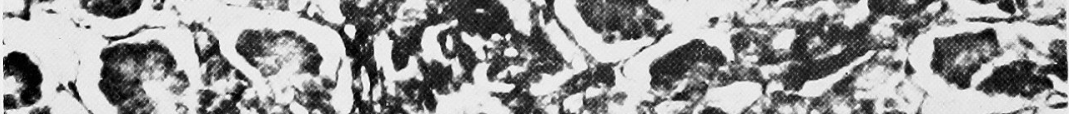

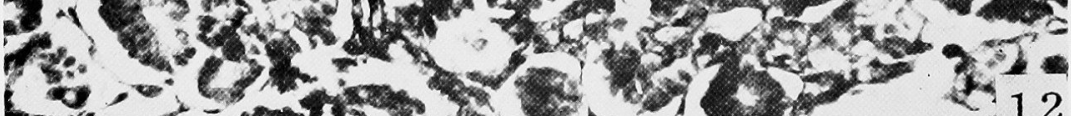

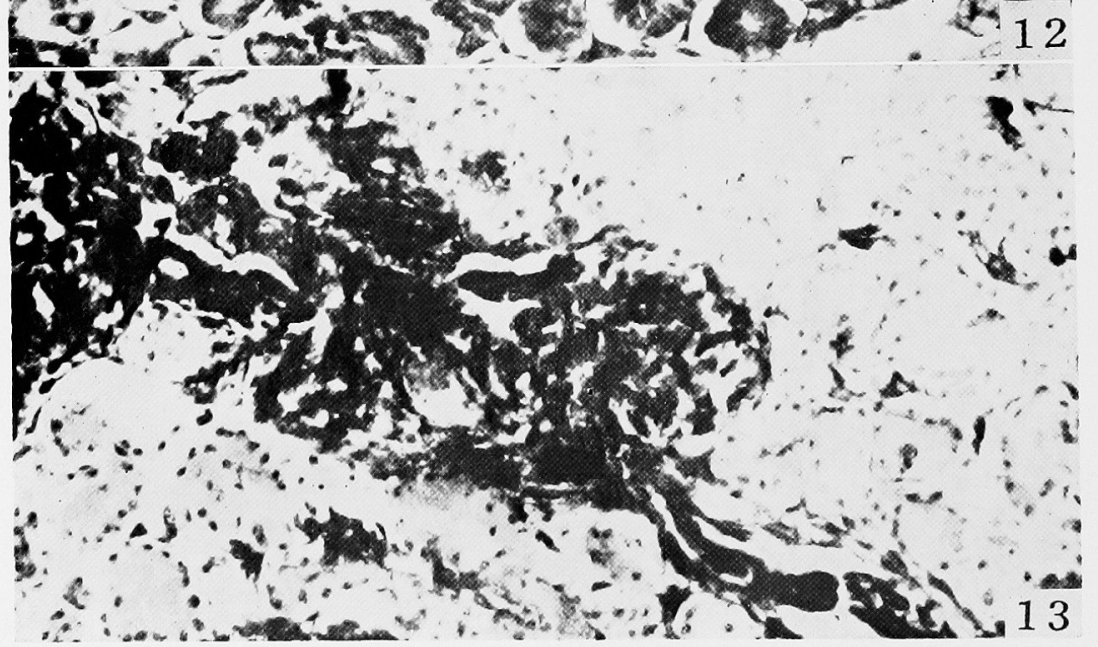

